Artigo original

Hegemonia - Revista Eletrônica de Relações Internacionais do Centro Universitário Unieuro

ISSN: $1809-1261$

UNIEURO, Brasília, número 10, 2012, pp. 77-91.

Recebido em: 3/4/2012

Revisado em: 2/5/2012

Aprovado em: 14/6/2012

\title{
O CONCEITO DE POLÍtICA E LIBERDADE NO PENSAMENTO DE HANNAH ARENDT
}

SILVA, Sandra Vieira ${ }^{1}$ e ARGUELHES, Delmo de Oliveira ${ }^{2}$

\section{Resumo}

O texto seguinte tem como objetivo perscrutar os conceitos de política e liberdade no pensamento de Hannah Arendt. Adotamos como ponto de partida, nesta breve incursão, a obra intitulada $A$ Condição Humana produzido pela autora em 1950. Todavia, outros trabalhos são aqui evocados uma vez que tais conceitos foram amplamente discutidos ao longo de todo seu pensamento.

Palavras-chave: Pensamento político, liberdade política; Hannah Arendt.

1 Mestre em História Social e das Ideias pela Universidade de Brasília (2004) e professora no curso de Direito do UniCEUB. 


\author{
Artigo original \\ Hegemonia - Revista Eletrônica de Relações Internacionais do Centro \\ Universitário Unieuro
}

ISSN: $1809-1261$

UNIEURO, Brasília, número 10, 2012, pp. 77-91.

\title{
I
}

As inquietações levantadas pela filósofa Arendt, acerca da temática política, estiveram intimamente relacionadas aos grandes problemas colocados no seu tempo. ${ }^{3}$ Não devemos esquecer que, na década de 1930, ela assistiu de perto a ascensão de um governo totalitário na Alemanha. Mais do que a ascensão do nazismo, o que provocou grande indignação em Arendt, foi o fato do estabelecimento desse regime ter ocorrido mediante o consentimento de grande parte da sociedade. Não só os alemães, mas praticamente toda a Europa, sentiria os efeitos desastrosos da admissão do nazismo, um dos grandes responsáveis pela eclosão da II Guerra Mundial. Nas décadas seguintes ao conflito, após sua compulsória vida no exílio, nos Estados Unidos, a filósofa presenciou a consolidação de uma política armamentista, adotada pelo Ocidente e Oriente cuja potencialidade colocava em xeque não só a liberdade, mas a própria existência humana. Foi diante de tais infortúnios de uma coisa política, que se ocupava com questões referentes à dominação e ao armamentismo,

2 Doutor em História das Ideias e Historiografia pela Universidade de Brasília (2008) e professor do Programa de Mestrado em Ciência Política da UniEURO e dos cursos de História e Relações Internacionais do UniCEUB.

3 A filósofa e pensadora política alemã Hannah Arendt (1906-1975) figura como uma das mais importantes pensadoras políticas do século XX. Viveu um dos mais conturbados momentos da história, do século passado, a Segunda Guerra Mundial. A implantação do regime nazista na Alemanha obrigou a filósofa, de origem judia, a se exilar nos Estados Unidos onde produziu uma vasta reflexão sobre a natureza política humana e os cerceamentos das liberdades em regimes totalitários como o nazismo, 0 fascismo e o stalinismo. Entre suas obras podemos destacar: As origens do totalitarismo, A condição humana, Entre o passado e o futuro, Da revolução, Eichmann em Jerusalém, Crises da república e, postumamente publicados, $A$ vida do espírito e $O$ que é política? 
Artigo original

Hegemonia - Revista Eletrônica de Relações Internacionais do Centro Universitário Unieuro

ISSN: $1809-1261$

UNIEURO, Brasília, número 10, 2012, pp. 77-91.

que Arendt passou a se perguntar se teria a política ainda algum sentido.

Para compreendermos a natureza desta indagação é necessário primeiramente procurar, ainda que sucintamente, delinear este conceito, tentando demonstrar o que a autora entende por política. Esta tarefa não será facilmente realizável, pois a idéia arendtiana acerca do tema destoa, em grande medida, dos consagrados modos de abordá-lo. Além de congregar consigo uma profusão de características bastante incomuns e atípicas ${ }^{4}$ à nossa compreensão atual do conceito.

Numa de suas reflexões, editada postumamente com o título $O$ que é política, a autora afirma que a política baseia-se na pluralidade de homens. A condição de existência plural para o estabelecimento de associações políticas contraria toda uma conduta do pensamento científico moderno que toma o homem, para efeito de reflexão, apartado dos demais de sua espécie. Sustenta a autora que

Para todo pensamento científico existe apenas o homem na biologia ou na psicologia, na filosofia e na teologia, da mesma forma como para a zoologia existe só o leão. Os leões seriam, no caso, uma questão que só interessa aos leões (...). A política [ao contrário do conceito isolado de homem e leão] trata da convivência entre diferentes. ${ }^{5}$

Para a filósofa, o homem não existe como homem quando se encontra completamente isolado. Nascemos, vivemos e morremos em meio a uma coletividade. A existência entre os indivíduos compreende

\footnotetext{
$4 \quad$ Referimo-nos às características atípicas como a convivência harmônica entre política e liberdade, no sentido empregado pela autora, pouco freqüente no pensamento político e acadêmico.

$5 \quad$ Hannah Arendt. O que é política. Rio de Janeiro: Bertrand Brasil, 2002, p. 21.
} 
Artigo original

Hegemonia - Revista Eletrônica de Relações Internacionais do Centro Universitário Unieuro

ISSN: $1809-1261$

UNIEURO, Brasília, número 10, 2012, pp. 77-91.

uma especificidade de suma importância, a qual não devemos neglicenciar, nem muito menos permitir que caia no esquecimento, quando nos propomos a pensar o domínio da política. A convivência plural traduz-se, nessa medida, como uma condição sine qua non de nossa existência como humanos. ${ }^{6}$ Nos depararemos assim, com o pensamento arendtiano condenando uma categoria de homem forjado filosoficamente e pensando independente dos demais. Por isso aponta para a superficialidade de um pensamento que, segundo ela "não revela outra coisa senão a própria ausência de profundidade na qual a política está ancorada"7 na convivência plural. Se o exercício político baseia-se na pluralidade de homens, ele só encontra sentido complementarmente se for vivenciado por indivíduos de existência livre.

Temos assim, o tema da liberdade introduzido como idéia indissociável do exercício político; por isso a autora afirma que o sentido da política é, senão outro, a liberdade. A existência política somente é possuidora de grandeza e dignidade, se exercida por sujeitos verdadeiramente livres. A idéia de liberdade, aqui empregada, implica no fato dos homens estarem liberados para ir e vir, pensar, falar e argumentar diante dos seus pares, ou seja, de outros que gozam da mesma condição. Tomada nesse sentido, esta idéia não nos permite, equivocadamente, inferir que em regimes totalitários, onde as

$6 \quad$ O pensamento do sociólogo Norbert Elias, muito especialmente em sua Sociedade dos Indivíduos, também rejeita a idéia de um homem pensado filosoficamente separado dos demais, e intitulado por ele como homo clausus. Nenhum homem nasce ou vive isolado; somos resultado de nossas relações que nos ensinam e envolvem e nos permite conviver em sociedade. Assim não há como analisar um homem fora da sociedade ou vice-versa, pois segundo Elias o homem só se faz homem entre outros homens.

$7 \quad$ Hannah Arendt, op cit., p. 21. 
Artigo original

Hegemonia - Revista Eletrônica de Relações Internacionais do Centro Universitário Unieuro

ISSN: $1809-1261$

UNIEURO, Brasília, número 10, 2012, pp. 77-91.

liberdades humanas são normalmente suprimidas, não haja política. Ela continua sim a existir, porém destituída de seu elemento mais fundamental. Articulando tais conceitos, a autora considera que a inevitabilidade de uma vida plural jamais deveria subtrair dos homens sua condição de libertos. Pelo contrário, a raison d'être da política não deve ser outra que a própria liberdade.

Nenhuma associação política é constituída por sujeitos iguais, isto porque nenhum homem é igual a qualquer outro existente ou que tenha existido no mundo. Vivemos coletivamente. As diferenças entre os homens, que se igualam somente na condição de libertos, devem no pensamento de Arendt ser administradas, não por meio de imposição ou coação numa comunidade política verdadeiramente digna; as diferenças são reguladas pelo uso da palavra e, mais precisamente, da persuasão.

O convencimento pela palavra, na comunidade política, compreende o único instrumento permitido, para o estabelecimento de um consenso em prol de um bem comum. Na pólis helênica, entendida como modelo exemplar de política, o uso de meios violentos para efeito de convencimento, no âmbito da coisa pública, era algo inadmissível. As comunidades que se fundavam na coação e na violência eram entendidas entre os gregos como associações pré-pólis; ou como acreditavam, bárbaras. Uma política conduzida sob a égide da liberdade, do agir plural e do convencimento pela persuasão, não perfaz uma quimera arendtiana, uma vez que tais significados foram, em grande medida, experimentados concretamente na antigüidade clássica.

Ao remontar a experiência da pólis, onde a política e liberdade emergiram como idéias sinônimas, Arendt intenciona compreender em 
Artigo original

Hegemonia - Revista Eletrônica de Relações Internacionais do Centro Universitário Unieuro

ISSN: $1809-1261$

UNIEURO, Brasília, número 10, 2012, pp. 77-91.

que momento histórico estes termos encontraram autonomia; e até se opuseram como no caso da Alemanha nazista. O fato de entender a experiência política na antigüidade grega, como o modelo a ser referenciado fez com que a autora, por vezes, fosse apontada com injusta propriedade de fazer uma reflexão nostálgica do mundo helênico; e também de sua proposição ser irrealizável na complexa sociedade contemporânea. É importante, para que não façamos julgamento de valor, lembrar que, o tempo todo, a autora esteve refletindo sobre problemas concretos colocados pelo século $X X$. O fato de remontar à política grega, não faz de Arendt uma helenista, por definição, nostálgica. Notemos, que mesmo afirmando que seu propósito não é, de modo algum, transpor o modelo político antigo para a contemporaneidade, mas sim o de reabilitar os sentidos políticos da pólis à luz das complexidades vigentes nas sociedades do seu tempo.

\section{II}

Para uma melhor compreensão de como a autora conduziu a esta proposição parece-nos importante nos reportaremos ao seu clássico trabalho intitulado $A$ condição humana. Nele, Arendt investigou três atividades fundamentais da condição, e não da natureza, humana situadas no âmbito da vita activa. A primeira delas, que chama de labor, diz respeito a toda atividade que visa satisfazer às necessidades permanentemente impostas pelo organismo. Assim como nos animais, o homem dedica-se ao labor para manter-se vivo, pois comer, beber e dormir, entre outros, são atividades que se prestam meramente à 
Artigo original

Hegemonia - Revista Eletrônica de Relações Internacionais do Centro Universitário Unieuro

ISSN: $1809-1261$

UNIEURO, Brasília, número 10, 2012, pp. 77-91.

conservação da vida. Este fazer esteve, entre os antigos, intimamente relacionado ao domínio das atividades menores da subserviência e da mortalidade; ${ }^{8}$ ações mortais porque seu resultado encerra-se em si mesmo, e nada acrescenta ao ser humano, além de uma fugaz manutenção das necessidades biológicas. É por natureza perecível. Infere assim, que a condição humana do labor é a própria vida.

A segunda atividade, denominada work, trata das ações humanas que convertem a natureza em artefatos para benefício material da vida no mundo. Apesar de estar associado, entre os antigos ao domínio das ações mortais, de alguma maneira seu produto compensava a transitoriedade da vida mortal. Esta compensação compatibilizava-se com o work, na medida em que a permanência do seu produto excedia, por vezes, o tempo de vida de seus executores. Contudo, o work encontrou-se colocado acima, na escala de valoração, do labor que esteve notoriamente marcado pela perecividade. A condição humana do work sustenta Arendt, é a mundanidade.

A action, por fim, é a única atividade por excelência da vita ativa exercida diretamente entre os homens. Sem intermédio de quaisquer outras coisas, tem como condição humana a pluralidade. Esta condição explica-se pelo fato de nenhum homem viver sozinho no mundo; nascemos e vivemos sob essa condição de existência plural. A action ocupa, assim, lugar central no quadro da vita activa, pois só a ação concreta de uma pluralidade de indivíduos, entendida como agir político, não se destina a nenhum tipo de necessidade, ela é deliberada

8 Começa a demonstrar, assim, três noções básicas e distintas entre si, são elas a mortalidade, imortalidade e eternidade. Todas elas serão caracterizadas ao longo deste texto. Cf. Hannah Arendt. A condição humana. Rio de Janeiro: Forense Universitária, 2001, pp. 15-78. 
Artigo original

Hegemonia - Revista Eletrônica de Relações Internacionais do Centro Universitário Unieuro

ISSN: $1809-1261$

UNIEURO, Brasília, número 10, 2012, pp. 77-91.

livremente e espontaneamente exercida entre os homens. A action traduz, assim, a atividade política por excelência no pensamento de Arendt. Nesse sentido sustenta que:

No idioma dos romanos - talvez o povo mais político que conhecemos - empregava como sinônimas as expressões 'viver' e 'estar entre os homens' (inter homines esse), ou 'morrer' e 'deixar de estar entre os homens' (inter homines esse desinere). (...) A pluralidade é a condição da ação humana pelo fato de sermos todos os mesmos, isto é, humanos, sem que ninguém seja exatamente igual a qualquer outra pessoa. ${ }^{9}$

Se pretendermos encontrar um significado para esse agir, não poderá ser outro senão a liberdade. O domínio da experiência política está relacionado à idéia de imortalidade. ${ }^{10} \mathrm{Em}$ Arendt, somente a partir desse exercício político de uma action plural, poderíamos superar dignamente a existência mortal, nos imortalizando por meio de feitos e palavras pela posteridade. A action é, nesse aspecto, a atividade política que nos permite alcançar a imortalidade. "A ação, na medida em que se empenha em fundar e preservar corpos políticos cria condição para a lembrança, ou seja, para a história." ${ }^{11}$

Foi este significado de vita activa, aqui descrito, que Arendt desvelou ao reportar-se à Antigüidade Clássica. Os gregos, explica a autora, conheceram duas esferas de existência bem distintas. A esfera

\footnotetext{
$9 \quad$ Ibidem, pp. $15-16$.

10 Este termo está no pensamento de Arendt associado à idéia de continuação de um feito e/ou pensamento no tempo.

$11 \quad$ Op. cit., pp. 16-17.
} 
Artigo original

Hegemonia - Revista Eletrônica de Relações Internacionais do Centro Universitário Unieuro

ISSN: $1809-1261$

UNIEURO, Brasília, número 10, 2012, pp. 77-91.

privada, $^{12}$ que compreendia o espaço doméstico, era proveniente das associações naturais, que se baseava em relações de desigualdade entre dominados e dominadores, ou entre senhores e subalternos. Tendo como ponto central a casa, oikia, ou a família, a existência do espaço privado destinava-se basicamente à satisfação das necessidades impostas pela vida material, prestando-se essencialmente às atividades de cunho laborioso. Somente os homens livres na condição de animal laborans, não estiveram fadados a confinarem-se de modo permanente neste mundo de atividades mortais. Aqueles que realmente eram livres precisavam transpor diariamente a esfera da família para ascender à esfera política, o domínio da dignidade. A este respeito Arendt escreveu que "essa liberdade, é claro, era precedida da liberação: para ser livre, o homem deveria ter se libertado das necessidades da vida." ${ }^{13}$ Neste contexto, a idéia de liberdade implicava não só no fato de estar liberado para ser realmente livre. No sentido mais amplo da palavra, era preciso estar na presença de outros e agir pluralmente entre 'iguais':

A liberdade necessitava, além da mera liberação, da companhia de outros homens, que estivessem no mesmo estado e também num espaço público comum para encontrá-los - um mundo politicamente organizado, em outras palavras, no qual cada homem livre poderia inserirse por palavras e feitos. ${ }^{14}$

12 O termo privado designa, aqui, a idéia de submissão do homem diante das necessidades e privações impostas no plano da vida material.

13 Hannah Arendt. Entre o passado e o futuro. São Paulo: Perspectiva, 1992, p. 194.

14 Idem. 
Artigo original

Hegemonia - Revista Eletrônica de Relações Internacionais do Centro Universitário Unieuro

ISSN: $1809-1261$

UNIEURO, Brasília, número 10, 2012, pp. 77-91.

As divergências de interesses que emergiam na esfera política, diferentemente do que ocorria no domínio privado, não eram solucionadas pelo meio da coação, nem tampouco da violência, mas sim, como já observamos, pelo uso da palavra persuasiva. As únicas atividades próprias dos bios politikos, em Aristóteles, era o discurso e a action, manifestados como recursos dialógicos de convencimento entre estes animales rationales. A pólis foi assim o único espaço onde os homens da antigüidade conseguiram imortalizar-se por meio da ação viva e concreta. A este respeito, Celso Lafer assevera que:

Liberdade, para Hannah Arendt, é a liberdade antiga relacionada com a pólis grega. Significa liberdade para participar, democraticamente, do espaço público da palavra e da ação. Liberdade, nessa acepção, e a política surgem do diálogo no plural (...), que permite a palavra viva e a ação vivida. ${ }^{15}$

Entre os antigos coexistiu além da concepção de mortalidade e imortalidade, a idéia de eternidade. O tema da eternidade aparece apontado no pensamento arendtiano atrelado, sobretudo, à filosofia política platônica. Desencantado com os negócios da pólis, sobretudo após a condenação de Sócrates, Platão passou a argumentar contra a coisa pública. Para ele o exercício da política era suplantado pelo ato contemplativo, tendo em vista que somente por meio da quietude plena, inclusive das ações políticas - skole: isenção de atividade política - o homem galgaria uma posição mais digna e elevada, que seria a eternidade.

15 Celso Lafer. Hannah Arendt. Pensamento, persuasão e poder. São Paulo: Paz e Terra, 2003, p. 31. 
Artigo original

Hegemonia - Revista Eletrônica de Relações Internacionais do Centro Universitário Unieuro

ISSN: $1809-1261$

UNIEURO, Brasília, número 10, 2012, pp. 77-91.

O problema da eternidade, colocado nestes moldes, aparece em Arendt como uma contraposição da política, pois esta forma de elevação absoluta somente se experiencia individualmente. Não devemos, aqui, nos esquecer que a idéia de política para a autora implica essencialmente numa action plural. Sendo assim, o alcance da dignidade passa não pela revelação individual, mas sim por um experimentar concreto em meio à pluralidade de homens.

\section{III}

Esboçado o quadro relativo à compreensão da condição humana, e da vida contemplativa na antigüidade, Arendt observa que historicamente todo este entendimento sofreu uma grande desfiguração ao deslocar-se e encaixar-se a outros significados. Com o desaparecimento da pólis antiga e a exaustão da res-publica romana, a expressão vita activa perdeu seu significado propriamente político. A raison d'être da política não mais coincidiu com a idéia de liberdade. Nos primórdios da medievalidade, a action foi rebaixada à estatura das necessidades, compartilhando o mesmo espaço com as atividades laboriosas. A concepção de cidadão, como homem atuante de uma esfera pública, caiu em desuso cedendo lugar a um novo tipo de homem, cuja liberdade manifestava-se, sobretudo, por meio da contemplação. Predominantemente, no medievo, a vida contemplativa passou a ser concebida como modo de vida, por excelência, que conduziria o homem à liberdade $O$ entendimento de liberdade, nesse sentido, se deslocou da terra para um plano celestial cristão. Assim, o 
Artigo original

Hegemonia - Revista Eletrônica de Relações Internacionais do Centro Universitário Unieuro

ISSN: $1809-1261$

UNIEURO, Brasília, número 10, 2012, pp. 77-91.

bios theoretikos assumiu o lugar antes ocupado pela vita activa política - bios politikos.

Se no mundo medievo a coisa política não mais encontrava prioridade no plano das atividades humanas, na era seguinte, conhecida como modernidade, este quadro tendeu a se agravar a partir da ascendência de uma esfera chamada de social. Na era moderna a sociedade emergiria das 'trevas' do espaço familiar, abolindo de vez o antigo abismo existente entre esfera pública e privada. Subvertendo a antiga hierarquia desses domínios, coube ao espaço público cuidar de assuntos de natureza estritamente particular como a preservação da propriedade. Enquanto na antigüidade a existência da propriedade permitia os homens participar da vida política, a modernidade conferiu a ela o estatuto de ethos último das ações humanas.

A ascensão do domínio social alterou radicalmente a condição humana perante o mundo da vida, já que o homem de atuação fora abolido cedendo lugar a outro tipo, que se isolou em si mesmo, e que não mais se dispôs a conviver ativamente com os demais, em proveito de assuntos comuns. Em Arendt esta individualização do homem atuante somente no plano dos interesses particulares, expressa a forma mais anti-humana de existência.

Quando uma pluralidade dos homens deixou de se ocupar dos assuntos que thes eram comuns, a coisa política converteu-se em assunto do estado nacional, onde encontrou seu novo formato. Nesse sentido, a grande prerrogativa da existência humana na era moderna, e ainda hoje, passou a ser o labor, que conceitualmente não mais se distingue do trabalho. Em um fragmento de $O$ Que é Política, a autora considerou que a coisa política converteu-se literalmente em coisa 
Artigo original

Hegemonia - Revista Eletrônica de Relações Internacionais do Centro Universitário Unieuro

ISSN: $1809-1261$

UNIEURO, Brasília, número 10, 2012, pp. 77-91.

econômica. Se na vita activa da pólis o labor foi a atividade que igualou os homens aos animais, na modernidade ela passou a ser a atividade que os diferenciava. A grandeza do trabalho foi expressa, com notório vigor, pela tradição de pensamento moderno, sobretudo por Marx que, para Arendt, foi um dos pensadores que mais se empenhou em converter o trabalho à categoria transformadora da existência humana:

A criação do homem através do trabalho humano foi uma das mais persistentes idéias de Marx desde sua juventude. (...) Fica claro no contexto que Marx realmente pretendia substituir a tradicional definição do homem como animal rationale chamando-o de animal laborans. ${ }^{16}$

\section{IV}

Todo este percurso reflexivo empreendido pela filósofa, acerca do tema da política e liberdade, não poderia de fato dissociar-se do grande mal estar gerado na época, sobretudo se vislumbrarmos a cena política internacional da segunda metade do século passado. Regimes totalitários e corridas armamentistas foram, sem dúvida, elementos catalizadores de tais reflexões. Entretanto, o pensamento aqui evocado revela-nos que toda a reflexão arendtiana, parece orbitar em torno de uma preocupação maior e mais específica. Incomodava a autora o fato de a humanidade eleger como finalidade última de sua existência a 
Artigo original

Hegemonia - Revista Eletrônica de Relações Internacionais do Centro Universitário Unieuro

ISSN: $1809-1261$

UNIEURO, Brasília, número 10, 2012, pp. 77-91.

fabricação. Alerta Arendt que, neste mundo onde tudo é sobrepujado pela coisa econômica, parece que não só a política e a liberdade perdem sentido, mas também a própria existência humana.

No momento no qual negligenciamos temas comuns aos homens e delegamos a terceiros a coisa política, nos isolamos em torno de atividades de interesse meramente particular, priorizamos uma condição humana marcada pela futilidade e perecividade. 0 isolamento, ${ }^{17}$ resultante do afastamento da coisa política, ressalta Arendt, destrói não só a capacidade humana de agir político, mas também a capacidade de sentir e pensar, de tal maneira que estes homens não mais conseguem discernir entre o bom do destrutivo, e o falso do verdadeiro. Por isso encontramos nas Origens do Totalitarismo, a autora argumentando que não há terreno mais fértil para o estabelecimento de regimes totalitários do que nestas sociedades, cujos homens encerram-se no isolamento. Isto torna bastante compreensível o caso do regime nazista, que ascendeu com o consentimento social e que, além de se curvar, o reverenciou como o regime que representava os interesses da coletividade alemã.

Ao se lançar ao isolamento e a existência laboriosa poucos se deram conta dos altos níveis de gravidade impostos por uma política armamentista que, ironicamente, possuía uma potência para destruir a humanidade. Diante de tais circunstâncias, Arendt indagou a respeito das possibilidades do homem reencontrar com uma experiência política fértil. No seu pensamento, este reencontro, somente seria possível

17 A concepção de isolamento em Arendt diz respeito ao isolamento do homem no que tange aos assuntos políticos e comuns, pois é claro que o homem não deixou de conviver socialmente com os demais, entretanto uma convivência social estéril que nada acrescenta à existência humana. 
Artigo original

Hegemonia - Revista Eletrônica de Relações Internacionais do Centro Universitário Unieuro

ISSN: $1809-1261$

UNIEURO, Brasília, número 10, 2012, pp. 77-91.

mediante o restabelecimento de um espaço público, como espaço de atuação política, livre e coletiva; pois, ao eleger a economia como centro da vida, o homem abriu mão não só de sua capacidade política, mas também de criar algo que acrescentasse um sentido digno e criativo ao mundo, e à sua existência efêmera.

\section{Bibliografia}

ARENDT, Hannah. Crises da república. São Paulo: Perspectiva, 1973. . Entre o Passado e o Futuro. São Paulo: Perspectiva, 1992. . Sobre a Violência. Rio de Janeiro: Relume Dumará, 1994. . O Que é Política. 2a edição. Rio de Janeiro: Bertrand Brasil, 1999.

. Eichmann em Jerusalém. Um relato sobre a banalidade do mal. São Paulo: Cia. das Letras, 1999.

- Origens do Totalitarismo. São Paulo: Companhia das Letras, 2000.

- A Condição Humana. 10 $0^{a}$ edição. Rio de Janeiro: Forense Universitária, 2001.

ELIAS, Nobert. Sociedade dos Indivíduos. Rio de Janeiro: Jorge Zahar Editor, 1994.

LAFER, Celso. Hannah Arendt. Pensamento, persuasão e poder. São Paulo: Paz e Terra, 2003. 